\title{
A28ＦRP 製ソフトボールバットの反発特性
}

\section{Restitution Characteristic of FRP Softball Bat}

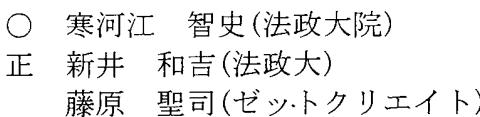

\author{
高橋大司朗 (法政大院) \\ 時枝 健一(ゼットクリエイト)
}

Satoshi SAGAE, Daishiro TAKAHASHI, Kazuyoshi ARAI, Hosei University, Kajino3-7-2, Koganei-shi, Tokyo Kenichi TOKIEDA, Seishi FUJIHARA, ZETT CREATE Corporation, Karasugatsuji 1-4-25, Tennoji-ku, Osaka

\begin{abstract}
Regarding softball bats made by fiber reinforced plastics (FRP), various products such as single-layer or multiple-layer structures have been developed. In this study, to elucidate the restitution characteristic of the FRP softball bat, the basic characteristics of five types of FRP bats and a metal bat were measured and softball impact tests of each bat were conducted. We investigated the relationship between the bat-ball coefficient of restitution (BBCOR) and the deflection or deformation of the bat and found that the BBCOR of the multiple-layer bat was greater than that of the single-layer bat, and the BBCOR of each bat was influenced by the deformation of bat at the ball impact point.
\end{abstract}

Key Words : Softball, Bat, FRP, BBCOR, Deformation

\section{1. 緒論}

現在，FRP(Fiber Reinforced Plastics)製のソフトボールバットは FRP単体，FRPの多重層構造など多種の製品が開発されている.金 属バットなどの野球バットでは, 中空シェル構造がボールとの衝 突時に変形し，復元時の力によりボールを反発させるというば权 の役割を担っている.このような打具とボールの間に柔らかいば ねを入れたことに相当する反発向上効果を，ばねがトランポリン の役割を果たしていると理解されることから「トランポリン効果」 と呼ばれている. FRP製のソフトボールバットの設計においても, このトランポリン効果を期待して打具のボールと直接接触する打 撃部の剛性を低減したり, 打球部分をFRPの多重層構造とする努 力が行われてきている(1).

そこで本研究では，FRP製ソフトボールバットの反発特性を解 明するために, 種々のFRP製ソフトボールバットを用いて基本特 性の測定を行った後, ボールの衝突実験を行い, 反発係数とバッ トのたわみ，および衝突点のバットの変形との関係について検討 した.

\section{2. 使用したバットの種類}

本実験で使用したソフトボール用バットは，アルミニウム合金 製の金属バット 1 種類，単層FRPバット 1 種類，3層FRPバット3種 類, 4層FRPバット 1 種類の計6種類のバットを各 3 本使用した. 各バ ットの略称を表1に示す。

\section{3. 実験}

3.1 バットの基本特性の測定法

バットの基本特性として，各バットの質量，全長，重心を測定 するとともに 1 次モードの節, 1 次, 4 次の固有振動数, 重心周 りの慣性モーメントの測定を行った。

質量は電子天秤((株)島津製作所製，PR8002)を用いて測定し，ス ケールで全長を測定した. 重心はバットを横に紐で吊り下げ,バッ トが水平となる位置を重心とした.

節の測定方法は，ゴム紐でバットを横に吊り下げ，バットと床 を平行にして加速度ピックアップ(PIEZOTRONICS(株製，PCB)を バットエンドに設置し，インパクトハンマー（PIEZOTRONICS森 製，PCB）を用いて測定した. 節の測定方法を図 1 に示寸.バット
の先端から $50 \mathrm{~mm}$ 間隔に 3 回ずつ測定し, その平均を算出した. また，節がある付近は $10 \mathrm{~mm}$ 間隔にて測定を行った。

固有振動数の測定方法は，節の測定と同様にピックアップを設 置しインパクトハンマーを用いて，バットの先端から $50 \mathrm{~mm}$ の位 置をハンマリングし, 1 次と 4 次の固有振動数を求めた.

重心周りの慣性モーメントを求めるために，まずグリップエン ド部を図 2 に示すような治具で吊るし，グリップエンドを中心に 振動させて, 周期を測定した. 周期の測定にはレーザ変位計 (三協 インタナショナル森製，LD1607-100）を用いた. 各バット10回ず つ測定を行い, 10 回のうち最大値と最小值を除いた 8 回の平均値 を算出した. 求めた周期 $T[\mathrm{~s}]$ から式(1)を用いで(2)グリップ周りの 慣性モーメント Ic $\left[\mathrm{kg} \cdot \mathrm{cm}^{2}\right]$ を求めた。

$$
I_{c}=\frac{T^{2} m_{2} g l}{4 \pi^{2}}
$$

ここで, $m_{2}$ はバットの質量 $[\mathrm{kg}], g$ は重力加速度 $\left[\mathrm{m} / \mathrm{s}^{2}\right], l$ はグリ ップエンドから重心までの距離 $[\mathrm{cm}]$ である. 上式により求めた $I_{\mathrm{c}}$ から, 平行軸の定理より, 式(2)を用いで ${ }^{(2)}$ 重心周りの慣性モーメ ント $I_{\mathrm{G}}\left[\mathrm{kg} \cdot \mathrm{cm}^{2}\right]$ を算出した.

$$
I_{G}=I_{c}-m_{2} l^{2} \quad \cdots \cdot(2)
$$

各バットの基本特性の測定結果をまとめて表 2 に示す. FRP-3C, FRP-4は重心位置がバットの先端側にあり，節の位置も先端側に ある傾向が分かった. また，FRP-3Bの固有振動数は他のバットよ りも顕著に低いことが分かる.

Table 1 Type and abbreviation of softball bat

\begin{tabular}{|c|c|}
\hline Type of bat & Abbreviation \\
\hline Metal bat & Metal \\
\hline Single-layer FRP bat & FRP-1 \\
\hline \multirow{3}{*}{ Three-layer FRP bat } & FRP-3A \\
\cline { 2 - 2 } & FRP-3B \\
\hline Four-layer FRP bat & FRP-3C \\
\hline
\end{tabular}




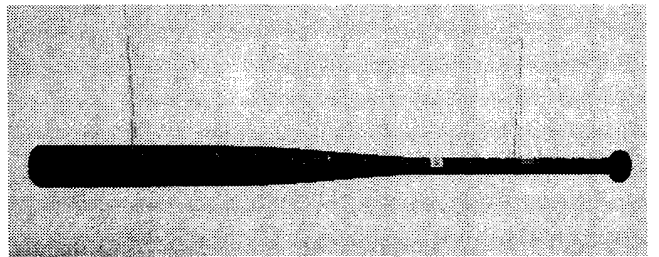

Fig.1 Measuring method of node

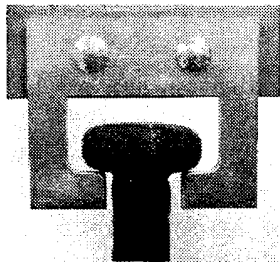

Fig.2 The jig for hanging a bat

Table 2 Result of basic characteristic of each bat

\begin{tabular}{|c|c|c|c|c|c|c|c|c|}
\hline \multirow{3}{*}{$\begin{array}{l}\text { Tipe of bat } \\
\text { Metal }\end{array}$} & \multirow{3}{*}{$\begin{array}{c}\text { Mass } \\
m \\
{[\mathrm{~g}]} \\
\\
733\end{array}$} & \multirow{3}{*}{$\begin{array}{c}\text { l.engti: } \\
{[\mathrm{nnn}]} \\
8+1\end{array}$} & \multirow{3}{*}{$\begin{array}{c}\text { Distance } \\
\text { from the tip } \\
\text { to a center } \\
\text { of mass } \\
l^{\circ} \\
{[\mathrm{mm}]} \\
336\end{array}$} & \multirow{2}{*}{\multicolumn{2}{|c|}{$\begin{array}{l}\text { Tode } \\
\text { Distance from } \\
\text { the tip[nm] }\end{array}$}} & \multicolumn{2}{|c|}{$\begin{array}{l}\text { A natural } \\
\text { frequency }[\mathrm{Hz}]\end{array}$} & \multirow{3}{*}{$\begin{array}{c}\text { Homent of } \\
\text { inertia with } \\
\text { respect to } \\
\text { the center } \\
\text { of mass } \\
I_{6} \\
{[\mathrm{~kg} \cdot \mathrm{cm}=2} \\
337\end{array}$} \\
\hline & & & & & & \multirow{2}{*}{$\begin{array}{l}\text { The } \\
\text { first } \\
194\end{array}$} & \multirow{2}{*}{$\begin{array}{c}\text { The } \\
\text { fourth } \\
2157\end{array}$} & \\
\hline & & & & 19 & 689 & & & \\
\hline FRP-1 & 719 & 841 & 77 & 19. & 695 & 206 & 1927 & 331 \\
\hline FRP $3 \mathrm{~A}$ & 719 & 841 & 337 & 191 & 694 & 202 & 1917 & 349 \\
\hline FRP 3B & 716 & 840 & 324 & 189 & 705 & 108 & 1540 & 327 \\
\hline FRP $-3 C$ & 744 & 840 & 291 & 158 & 685 & 226 & 2437 & 358 \\
\hline FRP 4 & 743 & 839 & 314 & 173 & 698 & 206 & $200 \%$ & 310 \\
\hline
\end{tabular}

\subsection{BBCOR の測定法}

バットの反発性能の評価のために，ボールがバットに衝突した 際の反発係数である BBCOR(bat-ball coefficient of restitution)を式(3) により求めた(3).

$$
B B C O R=-\left\{\frac{V_{2}}{V_{1}}\left(1+\frac{m_{1}}{m_{e}}\right)-\frac{m_{1}}{m_{e}}\right\}
$$

ここで, $V_{1}$ はボールの衝突速度 $[\mathrm{m} / \mathrm{s}], V_{2}$ は反発速度 $[\mathrm{m} / \mathrm{s}], m_{1}$ はボ 一ルの質量 $[\mathrm{kg}], m_{\mathrm{e}}$ はバットの実効質量 $[\mathrm{kg}]$ であり， $m_{\mathrm{e}}$ は式(4) を用いて求めた

$$
m_{e}=m_{2}\left(\frac{I_{G}}{m_{2} l^{2}+I_{G}}\right) \quad \cdots
$$

ここで, $l$ は打撃部から重心までの距離 $[\mathrm{cm}]$ である.

式(3)における，ボールの衝突速度 $V_{1}[\mathrm{~m} / \mathrm{s}]$ と反発速度 $V_{2}[\mathrm{~m} / \mathrm{s}]$ お よびその速度比 $V_{2} / V_{1}$ 在求めるために衝突実験を行った.ソフトボ 一ル用ボールの発射装置には，ガスガン方式のボール発射装置(高 压システム(纬)製)を使用した(5). 衝突現象の観測および速度測定に は，高速度ビデオカメラ(森フォトロン，FASTCAM-APX RS)を用 いた.

衝突実験はバットを図 2 の治具にグリップエンド部を支持して 吊るし，各バットの先端からの距離 $150 \mathrm{~mm}, 200 \mathrm{~mm}, 250 \mathrm{~mm}$, $300 \mathrm{~mm}$ ，および先端側の節の位置にボールを衝突させた.ボールの 衝突速度は $30 \mathrm{~m} / \mathrm{s}$ で一定とした。

\section{4. 結果および考察}

\subsection{BBCOR}

速度比とバットの先端からの距離との関係を図 3 に, BBCOR とバットの先端からの距離との関倸を図 4 にそれぞれ示す.各バ ットともに節付近において速度比および BBCOR が最大值を示し 節の位置における速度比および BBCOR は, FRP-4>FRP-3A> FRP-3C $>$ FRP-3B $>$ Metal $>$ FRP-1 の順に大きくなっている.多重 層構造のものほど BBCOR が高く，FRP-1 が最も低い傾向が見ら
れた. 積層構成が同一で単層構造とした FRP-1 と 3 層構造にした FRP-3A を比較すると, FRP-3A の方が BBCORが高くなっている. FRP-1 は FRP-3A と打球部分の総肉厚は同じであるが，単層で剛 性が高いため,トランボリン効果をあまり得ることができていな いと考えられる.これらのことより，打撃部の積層構造を多くする ことにより，金属バットよりもトランポリン効果を多く得ている と考えられる.

\section{2 バットの最大たわみと変形量}

バットのトランポリン効果について検討するため，各バットの ボール衝突時の最大たわみと衝突部の変形量について検討を行っ た. 各バットの最大たわみの測定法は, バットの側面に先端からグ リップエンドまで直線を引き，節の位置にも印をつけ，150mm, $200 \mathrm{~mm}, 250 \mathrm{~mm}, 300 \mathrm{~mm}$ の位置にボールを衝突させ，その時の バット全体のたわみを高速度ビデオカメラで撮影した. 図5に撮影 画像の一例を示した. 衝突時の高速度ビデオカメラ画像から，図6 に示すようにボールを衝突させた時の節と節を結ぶ直線と最もた わんだ点との距離を最大たわみ $y_{\max }$ とした.

最大たわみとボールの衝突位置の関係を図7に示す.FRP-3Bが 他のどのバットよりも大きくたわみ，その他のバットはほぼ同一 の值となった. また, 全てのバットにおいて節付近で最大たわみが 最小となっている.さらに, FRP-3Bのバットは, ボール衝突位置 が節付近からグリップエンド側ほど大きくたわみ，これはFRP-3B が他のFRPバットと異なり，ほぼ中央で2種のFRPが接合された構 造となっているためと考えられる。なお，バットのたわみと BBCORの間には相関が見られなかった。

各バットの先端からの距離 $150 \mathrm{~mm}, 200 \mathrm{~mm}, 250 \mathrm{~mm}, 300 \mathrm{~mm}$ お よび先端側の節の位置にボールを衝突させ，高速度ビデオカメラ の画像から, 図8に示すようにボール衝突部のバットの変形量 $L$ を測定した。

ボールの衝突箇所を変化させた場合の衝突点の変形量を図 9 および表 3 に示す. 全てのバットにおいて節付近の変形量が最も 大きい. 節位置における変形量は，FRP-4>FRP-3A > FRP-3B > FRP-3C $>$ Metal $>$ FRP-1 の順であり，この順は前述の BBCOR の順 とほぼ同一となっている.図 10 には, BBCOR と変形量の関係を 示寸. 全てのバットがほぼ同一曲線状にあり, 変形量が増加すると BBCOR も増加し, BBCOR と変形量との間には相関関係があるこ とが分かった。

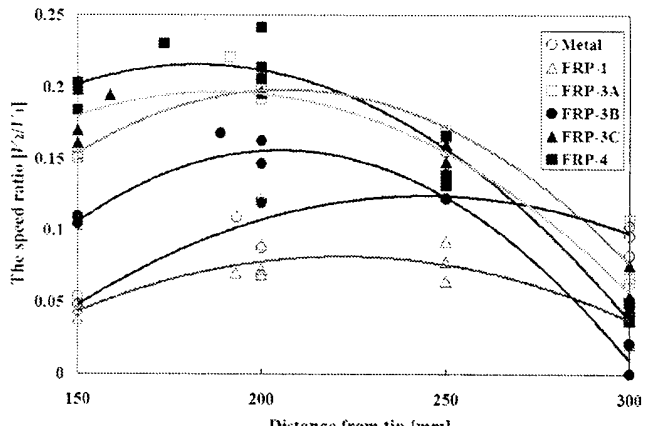

Fig.3 Relation between speed ratio and distance from tip

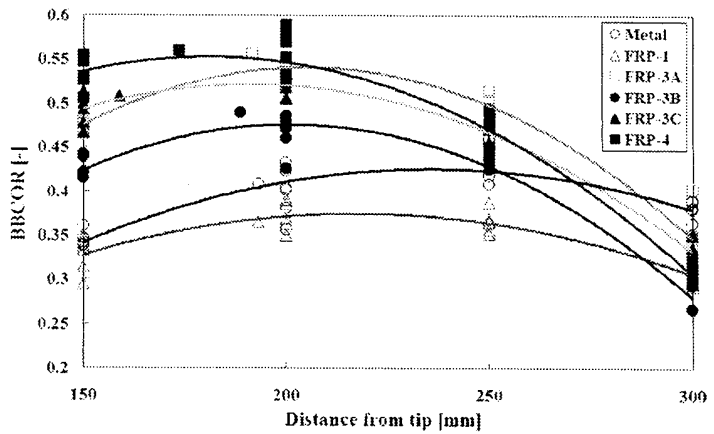

Fig.4 Relation between bat ball coefficient of restitution and distance from tip 


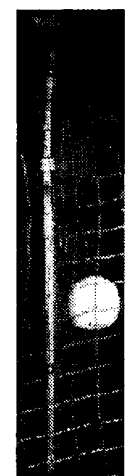

Fig.5 Image of high-speed camera

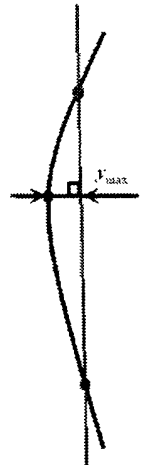

Fig.6 Measuring method of maximum deflection

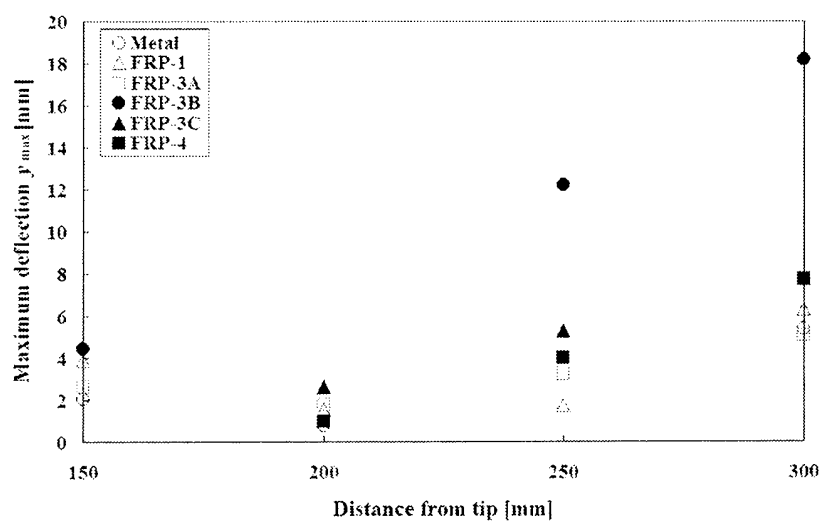

Fig.7 Relation between maximum deflection and distance from tip

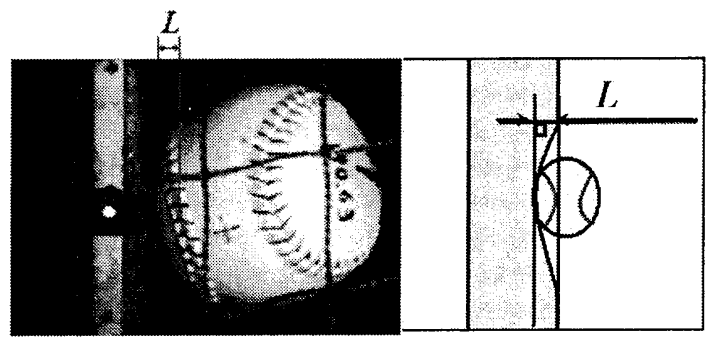

Fig. 8 Measuring method of deformation

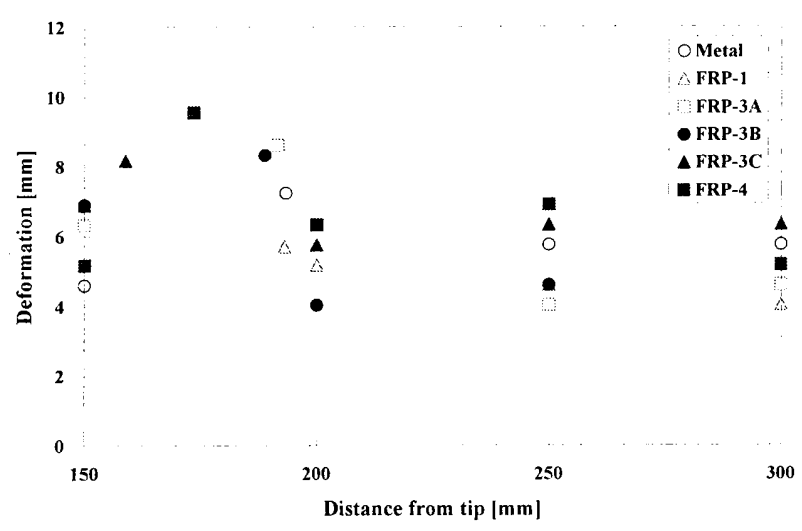

Fig.9 Relation between deformation and distance from tip

Table 3 Deformation of each bat by impact position of softball

\begin{tabular}{|c|c|c|c|c|c|}
\hline $\begin{array}{c}\text { Type of } \\
\text { bat }\end{array}$ & $\begin{array}{c}\text { Distance from } \\
\text { tip [mm] }\end{array}$ & $\begin{array}{c}\text { Deformation } \\
L[\mathrm{~mm}]\end{array}$ & $\begin{array}{c}\text { Trpe of } \\
\text { bat }\end{array}$ & $\begin{array}{c}\text { Dislance from } \\
\text { tip [mm] }\end{array}$ & $\begin{array}{c}\text { Deformation } \\
L[\mathrm{~mm}]\end{array}$ \\
\hline \multirow{5}{*}{ Metal } & 150 & 4.60 & \multirow{5}{*}{ FRP $-3 B$} & 150 & 6.90 \\
\hline & (Node) 193.3 & 7.23 & & (Xode) 188.8 & $\underline{8.32}$ \\
\hline & 200 & 6.32 & & 200 & 402 \\
\hline & 250 & 5.75 & & 250 & 4.60 \\
\hline & 300 & 5.75 & & 300 & 5.17 \\
\hline \multirow{5}{*}{ FRP-1 } & 150 & 5.17 & \multirow{5}{*}{ FRP-3C } & 150 & 6.90 \\
\hline & (Node) 193 & 5.69 & & (Node) 158.8 & 8.17 \\
\hline & 200 & 5.17 & & 200 & 5.75 \\
\hline & 250 & 4.60 & & 250 & 6.32 \\
\hline & 300 & 4.02 & & 300 & 6.32 \\
\hline \multirow{5}{*}{ FRP-3A } & 150 & 6.32 & \multirow{5}{*}{ FRP-4 } & 150 & 5.17 \\
\hline & (Node) 191.6 & 8.62 & & (Yode) 173.5 & 9.56 \\
\hline & 200 & $\overline{6.32}$ & & 200 & 6.32 \\
\hline & 250 & 4.02 & & 250 & 6.90 \\
\hline & 300 & +.60 & & 300 & 5.17 \\
\hline
\end{tabular}

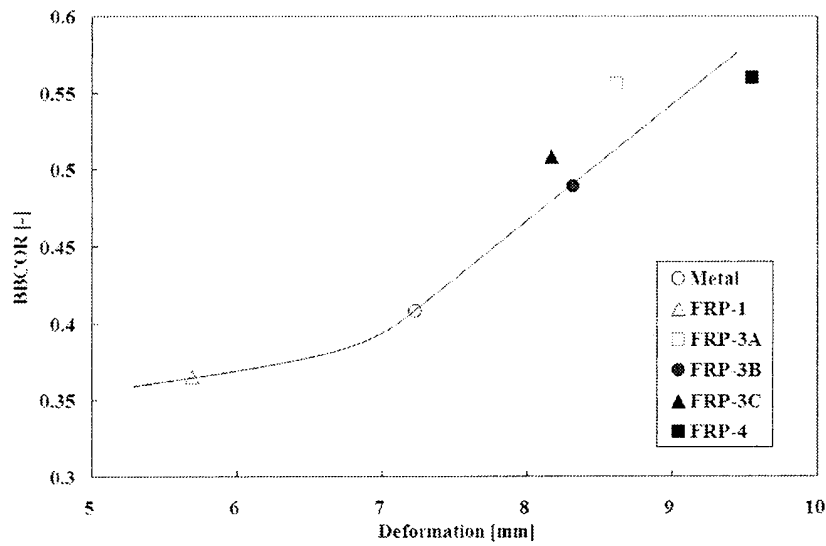

Fig. 10 Relation between BBCOR and deformation

\section{5 結論}

FRP製バット 5 種類および金属バットの基本特性を測定す るとともに，ボールとの衝突実験を行い，BBCORとバットの たわみ,ボ一ルの衝突部の変形量との関係を検討した.その結 果, BBCORはFRP多重層構造のものが大きく，次いで金属バ ット, FRP単層の順であった.また, BBCORはバットのたわ みではなく，ボールの衝突部の変形量に大きく影響されるこ とが分かった。

\section{参考文献}

(1) 神田芳文, 鳴尾丈司, 軟式野球バット打撃部のトランポリ ン効果, 日本機械学会シンポジウム講演論文集, No.08-23 (2008), pp.92-97.

(2) A. Terry Bahill, The Ideal Moment of Inertia for a Baseball or Softball Bat, IEEE Transactions on Systems, Man, and Cybernetics-Part A: Systems and Humans, Vol. 34, No.2 (2004-3), pp. 197-204.

(3) ASTM Designation: F2219-09, Standard Test Methods for Measuring High-Speed Bat Performance.

（4）日本機械学会編, 機械工学便覧, 基礎編 $\alpha 2$ 機械力学 (2004), p. $\alpha 2-31$.

(5) 冨岡, 新井, 関, 森田, 岩原, 長松, 硬式野球用へルメット の繰り返し衝突に対する緩衝性能, スポーツ産業学研究, Voi.19, No2 (2009), pp.105-111 